\title{
A Qualitative Study of Gender Issues Associated With Academic Mentoring in a Nigerian University
}

\author{
Oghoadena Clementina Osezua \\ Obafemi Awolowo University \\ Damilola T. Agbalajobi \\ Obafemi Awolowo University
}

\begin{abstract}
There is an upsurge in the establishment of private and public universities in Nigeria. The development has opened up the need for quality and seasoned academics, but minimal opportunities exist for mentoring of young academics. This article explores the mentoring opportunities and challenges of young female academics faced in a male dominant university system. From an exploratory qualitative design, this article generates empirical evidence through structured a face-to-face interview with purposively selected 36 female academics. The participants were recruited from the Obafemi Awolowo University, a first-generation, public-owned university in Nigeria. A thematic analysis of the data revealed common challenges in mentoring female academics as inadequate and non-availability of older female role models for upcoming female academics. Other factors include fear of being stigmatized by other colleagues when a female has a male as an academic model, unfriendly gender policies, and work environment that will not cater for women's needs (especially those in their reproductive age). Based on these findings, the article calls for more formal mentoring relationship for younger women academics. Such step will create a sense of purpose and provide requisite information that will enhance their career progression.
\end{abstract}

Keywords: mentoring, female academics, gender, university, Nigeria

\section{Introduction}

The astronomical rise in the number of universities in Nigeria in the last few years attests to the urgency placed by the Nigerian government of the need to fast-track development of quality and accessible higher education for her citizens (Famade, Omiyale, \& Adebola, 2015). This development has also led to mass recruitment of academics of which significant percentages are young female academics, even though still relatively low. A report on the mass shortage of academics has been reported in many Nigerian universities. More obvious is the huge gender disparity in many universities. For instance, the International Organisation for Migration (2014) Need Assessment Report revealed that only $18 \%$ out of the $83 \%$ recruited academics are women. This has implication on the nature of the work environment which becomes less receptive to the need for gender mainstreaming in the structure and access to resources that can improve the research capacities of female academics. The creation of a mentoring system for male and female academics has been identified as a step in the right direction of mainstreaming gender into the Nigerian university system. Despite these calls, the assumption remains that young male and female academics can enjoy optimal benefits from a homogenous mentoring process. 
Mentoring is a germane avenue through which professional skills can be acquired, for developmental purposes and effective career progression by young academics. Mentoring is an important avenue through which academic standards can be maintained and sustained. Although there is still a wide gender gap in recruitment of female academics, the recent $30 \%$ affirmative action has stimulated an increase in recruitment of female academic staff in Nigerian university system presently. Incidentally, the university system in Nigeria is largely male dominant. Very few females are at the upper echelon of both administrative and academic positions. A high proportion of young female academics are at a lower cadre (Bush, 2006), which implies a gross need of academic mentoring. Such priceless nurturing can be tapped from the residual and declining pool of older female academics. A key criterion for promotion of academics in the Nigerian university system is research and publication. Over the years, the standards expected of all academics have increased; yet, the process of attaining the skills and required knowledge for scientific writing remain grossly inadequate (International Organisation for Migration, 2014). Both young male and female academics suffer from the paucity of formal mentoring process in the university system. Nonetheless, the social dynamics of surviving as a female academic are dissimilar from that of the male. As such, it will be absurd and noneffective to presume that a homogenous mentoring system for male and female academics.

Certain cultural demands alongside with organizational culture expose male and females to differentiated competing social demands. These variations also act on their capacities to survive the demanding completion in the academia. In patriarchal settings, women are socialized into supportive roles that might not add direct benefits to their personal progress or career aspirations. Nonetheless, the pressure to perform these roles comes from all directions. Conformity to these social pressures is often exhibited in several ways. For the married young female academics, their traditional domestic roles clash with their desire to make the requisite sacrifices needed for an uninterrupted career progression. Diverse pressures are also overt in heterosexual marriages where women are sometimes expected to sacrifice their personal aspirations and career development. Marriage and childbearing are particularly esteemed cultural elements within many Nigerian societies. Hence, younger women are generally socialized to place premium on their homes and marriages above every other consideration. In this direction, Oluwole, Hammed, and Awaebe (2010) noted that women make conscious efforts to support their significant others toward achieving life goals. Despite the social expectation and commitment of some women to the course of their significant others, similar gestures are often lacking towards women's career. Meeting such career demands, within the Nigerian context can have obvious toll her domestic responsibilities of younger women who are academics. Unwillingness to play this submissive role could attract condemnation and harsh criticisms from significant others and coworkers.

However, promotion criteria and the stiff completion in the university system remain blind to these social dynamics and survival challenges. Competing favorably with male colleagues in the Nigerian universities where promotion criteria remain largely gender neutral remains an uphill task for several young female academics. With publication output as critical to promotion in the ivory towers in Nigeria, Ogbogu (2009) documented the huge gender disparity in academic publications of Nigerian academics in international learned and refereed journals. This may be attributable to the absence of adequate mentoring for young female academics which should increase their survival within a hostile-male-dominated work environment. The implications include unending struggle to acquire relevant skills in research and scientific writing and confusion in the search for credible publication outlets. Interestingly, the number of disreputable journals has increased over the years with limited guidance for inexperienced researchers. The existence of poor integration process and inadequate mentoring process will therefore increase the struggle to survive in the academia. 
Against this backdrop, this article explores the experiences and challenges of securing an academic mentor as a young female academic in a first-generation university. The availability and access to a unique mentoring system remains crucial to career advancement and positioning of females in decision making roles in the university system. The following questions arising from the objectives will give direction to the study if adequately answered:

Research Question 1: What are perceived prospects and challenges faced by younger women in securing academic mentors as female academics?

Research Question 2: How accessible and available are mentoring opportunities for young female academics?

\section{Literature Review}

Mentoring has a long tradition in higher education. In the traditional academic model, a professor with notable achievements in a discipline may seek out younger colleagues or students to nurture their development. From personal observation, mentees are encouraged to undertake particular researches, write part of an article or a book with joint contribution or become research assistants on large projects. In the processes associated with mentoring, skills in research and writing are taught and opportunities to attend conferences or meetings are shared, while information on funding or sourcing other forms of support is provided. Consequently, the younger partners or mentees in this context learn to "decode" the corporate culture in existence in such organizations (Geber, 2004). Megginson (2006) described mentorship as offline help by one person to another in making significant transitions in knowledge, work, or thinking, either through sponsorship from the more senior colleague with the aim to facilitate learning rather than provide answers that will enhance the career development of the younger colleague.

In the academic cycle, mentoring is considered imperative by many scholars to minimize occupational stress and help reduce conflicts that may arise as younger academics fight to attain a healthy work-life balance and make positive, steady professional accomplishments (Winesfield \& Jarret, 2001). While Connor and Pokora (2007) maintained that mentoring is a learning relationship that helps people to take charge of their own development, release their potentials, and achieve results they value. Mentoring also presents vigorous collaborations and collegiality. In the Nigerian university system, coordinated mentoring system is grossly lacking. No significant effort or policy has been put in place to respond to the urgent need for differentiated mentoring process for young males and female academics. The gender inequality in the representation of females in decisionmaking roles cuts across various sectors of the Nigerian society. In response, the National Gender Policy aimed to address the gap by increasing the threshold of women in leadership positions by $35 \%$. Despite the loftiness of this aim, no concrete steps are in place to ensure the realization of these objective gaps (Federal Ministry of Women Affairs and Social Development, 2006).

In Nigeria, the disparity in the ratio of male to female academics remains very high. For instance, in the 2001/2002 session, the total number of Nigerian university teachers was 20,124, and out of this number, 3,174 (15.7\%) were females, while 17,040 (84.3\%) were male. A study at the University of Benin in Southern Nigeria also revealed a ratio of eight male academics to one female. The very chilly environment female academics have to operate in serves as a potential drawback toward achieving professional goals and enjoying a healthy career progression in their area of specialization (Ofoevwe \& Agbontaen-Eghafona, 2011). The study also disclosed that in several instances, possibilities of mentorship relationship transiting into a romantic relationship were also rife in the 
universities. This further accentuates the need to interrogate the challenges associated with mentormentee relationship, from the perspectives of the social actors themselves.

The mentoring experiences and survival challenges of the few young female academics in the Nigerian university system remain poorly understood. A few findings have documented the lack of formalized structure in mentoring relationship, thereby excluding several other (Okruramen, 2008) and that men can hardly provide psychosocial function, which women need (Okruramen, 2006). Other studies like Oloruntoba and Ajayi (2006) and Ofoevwe and Agbontaen-Eghafona (2006) observed the disadvantage position of female academics in mentoring relationships arising from gender stereotypes. For academics, mentoring can contribute to an individual's career development in the field, particularly in areas of research, publications, and promotion, by providing junior academics with a means to find out more about career management and institutional networking (Allen, Eby, Poteet, Lentz, \& Lima, 2004). Levinson, Kaufman, Clark, and Tolle (1991) found in a study of female academics in the United States that women with mentors had more publications and spent more time on research than women without mentors. Women with academic role models also reported higher overall career satisfaction. Additionally, Wasserstein, Quistberg, and Shea (2007) reported that in a cross-sectional self-administered survey of 1,046 faculty members at the University of Pennsylvania School of Medicine, mentoring was strongly correlated with overall job satisfaction. Evidence, however, suggests that men have engaged more frequently in informal mentoring in the workplace than their female counterparts (Kanter, 1977), while women find it more difficult in engage in informal mentoring (Sambunjak, Straus, \& Marusic, 2006). The recurring constraint of role models or mentors in the Nigerian university system requires contextual understanding and solution.

\section{Theoretical Framework}

\section{Theory of Benevolent Sexism}

The theory of benevolent sexism was proposed by Glike and Fiske (1991) in explaining systemic oppression that has culminated in underrepresentation of women in complex organizations. The university system is characterized by a series of complexities similar to what exist in large corporations. In the theory, Glike and Fiske identified the notion of sexism as an underlying basis to understand hostile and benevolent reactions and decisions in the work place. In their opinion, sexism is reinforced in the network of relations within social structures. Such supports are more conspicuous in social settings where gendered relations are dominated by patriarchal ideologies. In such settings, the authors argue that dominant beliefs and gender norms are driven by these social expectations and thus make it difficult for women to challenge the status quo. This has a lot to do with socialization which reinforces the attitude of compliance, submission, and passivity associated with women.

This sexist conception portrays women outside the domestic enclave as incapable, lacking requisite cognitive ability. Interestingly many educational institutions are built on this sexist conception thereby relegating the potentials of women for higher positions. The university system in Nigeria is fundamentally similar to many other tertiary institutions that have refused to change this skewed gender orientation. For instance, university is a colonial heritage in Nigeria and has limited features of gender mainstreaming to date. Arguably, during the colonial era, women became unemployable (McIntosh, 2009), thereby serving as a prelude of existing gender inequality in the workplace including the university system (Uwaezuoke \& Ezeh 2008). Many of the Nigerian firstgeneration universities established between 1960 and1970 were done so based on an inherited 
British culture that further accentuated gender roles and also did not give advantage to women in many Nigerian universities because of a low level of education.

Indeed, men constitute the larger percentage of those who constitute the management core of many Nigerian universities. It is therefore not surprising where there are no formalized mentoring systems which can actually take into cognizance the critical needs of the female who are grossly underrepresented in the academia despite the National Gender Policy insistence of the 35\% minimum threshold.

A part of the benevolent sexism theory addresses the compliance and passivity of many women, which is a form of system justification for sexists' ideology. The sexist theory provides greater attention to the underlying ideology that explains why the university structure is not gender sensitive.

\section{Methodology}

The study engaged an exploratory research design. This approach enables us to pay attention to the social context and the interpretations given by the participants to mentoring experiences and coping measures within the context of a highly gendered space. As such, an interview guide was developed based on these themes: perception toward the value in academic mentoring and academic women's experiences in relation to challenges potentially inherent in the mentor-mentee relationship.

In exploratory qualitative designs, the views of participants are sought more closely, so that insights can be gained into what they think and feel in relation to the question of interest (Smith, Flowers, \& Larkin, 2009). The study site is Obafemi Awolowo University (OAU), a first-generation University in Southwestern Nigeria. First-generation universities are those universities that were established shortly after the Nigerian independence to meet the manpower needs of the newly independent British colony. Other universities in this category include the University of Ibadan, the Ahmadu Bello University, and University of Lagos. The OAU was formerly known as the University of Ife. The university was established in 1962 with an initial student population of 244, academic staff of 64 , and administrative and technical staff of 15 . The university started with five departments, namely agriculture, art, law, science, economics and social studies (now Faculty of Social Sciences). However, eight new departments have been added: education, pharmacy, technology, basic medical, clinical sciences, dentistry, administration, environmental design and management (Obafemi Awolowo University, , 2016). Over the years, the university student population has grown to about 35,000.At the end of the 2013 academic session, OAU had 1,241 academic staff (1,049 males and 192 females).The ratio of male to female lecturers as of the 2013 academic session reveals a vast underrepresentation of women in terms of staff recruitment.

The study purposively selected young female academics based on two criteria: (a) those who are enrolled in a postgraduate program like Masters programme or who have just concluded their doctoral studies within the last 6 years and (b) those who have just been recruited as academic staff who have no doctorate degree. This selection is based on their noveau experiences as academic staff in the university setting. A total of nine departments were covered. Observably, there appeared to have been a higher concentration of young women academics in the social sciences and education departments, with fewer women in the physical-science-related disciplines. In all, a total of 36 academic staff members were interviewed. The average length of the interview sessions was 45-70 $\mathrm{min}$. The interviewees were allowed to choose the location for the interview. Verbal consent was obtained from each participant in the conducted interviews, and anonymity was also guaranteed by the decision to use pseudonyms. Interview questions focused on their perception toward mentoring; 
career progression prospects, challenges, opportunities, and constraints in the work environment; and their assessment of gender responsiveness of the university environment in regard to female academic career growth and productivity. Many of the young women expressed a sigh of relief, suggesting that some of them had the opportunity to vent their frustrations and lend their voices on issues of their career progression and family life.

\section{Data Presentation and Analysis}

Interviews were transcribed verbatim by the first author to get a sense of the data, assess the completeness, and identify new themes not initially considered in the interview guides. Based on the interview guides, themes coding categories were identified. All coded transcripts were checked for consistency as suggested by Woods et al (2002). The coded segments were checked by academic qualification/status and range of mentoring experiences. Finally, representative quotes were selected, and extracts were used to represent trends and experiences of the interviewees.

\section{Profile of the Study Participants}

An appreciable proportion (32) of the study participants are married, with only two being single. Seventeen of the young academics had spent 6 years or less in the university, and 19 were still undergoing their master's programs. The university regards academic staff undergoing postgraduate studies as trainees. Only five had completed their doctorates. One of them was employed in academia only 6 years ago, which suggests that there was a need to interview such a person. Furthermore, a significant proportion of the participants was drawn from social sciences and education, as both departments record a tangible presence of female academics. Indeed, the core sciences had considerably fewer women (see Table 1).

\section{Perceived Prospects of Mentoring Among Academics}

All the participants were unanimous in their opinions about the utility of mentoring for female academics. They observed that mentoring was essentially vital for academics to be able to compete globally and acquire requisite competence needed for effective transmission of knowledge. The interviewees were asked about the importance of mentoring. Find below the excerpts:

Mentoring.....Very, very, important. This is because our promotion is based on publications one makes. You don't really have breakthrough unless you see somebody who has gone through the path. If you don't seek counsel you might fall into ditch. (Mrs. B.; Faculty of Social Science)

Very important. For you to live and survive in an ocean you need to be taught. In life you must go through training and counseling. Life is about hard work and being smart. It is not about hard work alone you have to be smart too. You must be humble to have a good relationship and to be able to scale through. (Dr. [Mrs.] J.; Faculty of Arts)

If you are in academics and you lack mentoring, it is like a ship without a compass. Mentoring opens your eyes and you will learn how to go about things. It is very important. (Dr. [Mrs.] S.; Faculty of Education) 
Table 1: Sociodemographics of Selected Female Academic Participants (2013 Field Survey)

\begin{tabular}{|c|c|}
\hline & Frequency \\
\hline \multicolumn{2}{|l|}{ Age range } \\
\hline $25-30$ & 6 \\
\hline $31-35$ & 10 \\
\hline $36-40$ & 4 \\
\hline $41-45$ & 14 \\
\hline $45+$ & 2 \\
\hline Total & 36 \\
\hline \multicolumn{2}{|l|}{ Length in years } \\
\hline $1-3$ & 10 \\
\hline $4-6$ & 7 \\
\hline $7-9$ & 14 \\
\hline $10-12$ & 3 \\
\hline $13-15$ & 2 \\
\hline Total & 36 \\
\hline \multicolumn{2}{|l|}{ Qualifications } \\
\hline Ongoing MSc & 19 \\
\hline Ongoing PhD & 12 \\
\hline Completed $\mathrm{PhD}$ & 05 \\
\hline Total & 36 \\
\hline \multicolumn{2}{|l|}{ Faculties } \\
\hline Health sciences & 3 \\
\hline Pharmacy & 5 \\
\hline Administration & 2 \\
\hline Arts & 4 \\
\hline Sciences & 4 \\
\hline Education & 7 \\
\hline Social sciences & 9 \\
\hline Agriculture & 2 \\
\hline Total & 36 \\
\hline \multicolumn{2}{|l|}{ Marital status } \\
\hline Single & 4 \\
\hline Married & 32 \\
\hline
\end{tabular}

Most participants (25) specifically affirmed the highly patriarchal nature of the university system, which does not take into cognizance the presence of the younger female academics, while the other seven interviewees were indifferent to dominance of male academics as a threat to productivity. Four others stated that the work environment was unfavorable to both males and females.

The origin of the university especially as it in Nigeria did not really pay attention to the female gender as active stakeholder. Look at the infrastructures provided, and see whether women needs were put into consideration. Even some words used make you know that it's essentially a place that is dominated by men, take for instance the use of the word, fresh men. It completely summarized the constitution of the university as unfriendly to females, whether students or workers. (Mrs. K.; Faculty of Health Sciences) 
Even as a student, as a young lady you will notice that even the basic needs of having to use bathrooms did not take into cognizance the basic gender needs of a young girl like having constant water when she is on (menstruating) or seen providing generous volume of tissue. You can imagine that. You are expected to work so hard and sometimes harder than a man to be able to move up because even the promotion criteria don't care if you are a woman or man. It is really hostile to women somehow. (Mrs. L.; MSc student, Faculty of Education)

On the other hand, a few of them were ambivalent about male dominance can affect women's access to mentoring opportunity. Rather, they attributed most of the challenges to lack of funding to provide physical infrastructures, relevant facilities to aid teaching and learning, and shortage of man power. They opined that the government's insincerity to providing quality education is attributable to present state of tertiary education.

I do not think our problem has to do with whether you are male or female but that we lacked facilities, no proper funding from the government. There is presently acute shortage of staff, the staff ratio is extremely poor. So it's all about the survival of the fittest. And since they appear to be more, they will tend to grapple with the very scarce resources. (Mrs. M.; Faculty of Health Sciences)

As for me, I don't believe in gender matters like that. I feel the problems in our university have more to do with political economic situation of the country as a whole and off course the university is a macrocosm. Education is not a top priority to government and this has also made the university system nonchalant to delivery of qualitative tertiary education. There are issues related to funding, males and female lecturers, gender notwithstanding cannot access funds to carry out their research not to talk of attending conferences, workshops and scientific seminars. It's beyond mentoring, with what will those who want to mentor, mentor. Many of them are out there chasing consultancy opportunities so as to make ends meet.

(Miss S.; Faculty of Sciences)

All the interviewees were unanimous in the areas where mentorship is needed. Some of the core areas identified are publication-related matters-writing journal articles, developing good writing skills, data analyses, writing reports, and identifying credible outlets for journal publications. Others included providing information about conferences, teaching skills and time management, as many women multitask.

Writing skills and research skills: Sometimes, the people that are my mentors tell me that there is paper we will write together and put your name. They sometimes help through analysis. Through these I get to learn something new. (Mrs. B.; PhD candidate, Faculty of Social Sciences)

Research publication: I would have improved in my area of teaching too. If I am disturbed somehow, my mentor would be there to encourage me in my teaching skills. The area of time management, (thesis, report and research) research work generally. Men have time; they can leave their homes in the morning and be in the office till 7 p.m. But women don't have that time. We 
run up and down for our children to go to school and we get tired after doing a little work. At the end of the day, papers and thesis are left unwritten, coupled with emotional and psychological problems. It is worse if a woman is married to a nonacademic who might not understand the job very well. We may not meet up $100 \%$, at least $80 \%$. (Mrs. S.; PhD candidate, Faculty of Social Sciences)

Publication: Some of my mentors gave me journals where they are editors and co-editors. They gave me textbook, newspaper. Some tell me what to do and not to do. They download materials for me. I was looking for a textbook that cost N4,000 and one of my mentors, a professor bought it for me. (Dr. [Mrs.] S.; Faculty of Education)

Writing, publications, data analysis, editing: The mentoring I had actually helped me in writing. While in Nairobi, they taught us to always seek for mentors outside the shores of Nigeria and I have quite a number of them. Better journals. I would have had better journals. It was until recently that I was opportune to publish on journals that enjoy more audience. (Dr. [Mrs.] O.; Faculty of Pharmacy)

It (female academic mentoring) is needed, because if there is no mentoring it will be hard for you to go about academics, a young female academics, you don't just publish for publishing sake, you need to be mentored in order for you to know what to do and how to do them in academics. (Mrs. F.; Faculty of Pharmacy)

Publication, they will just tell you how and where to publish your papers and also inform you of areas to publish. (Dr. [Miss] G.; Faculty of Health Sciences).

Paper writing: Because they supervise. Publication sometimes. When you see people collaborate, you will be 80percent sure that the younger one wrote the paper and put the professor's name. In time management, they take your time. They don't teach us how to teach. Most times when you are paired up with professors to teach, the younger lecturer ends up doing most of the teaching. (Mrs. K.; Faculty of Social Sciences)

Although many of them agreed that they needed help in, scientific academic writing, this may be based on the very popular axiom in the ivory towers in Nigeria: Publish or perish. A number of the participants also identified the importance attending academic conference especially information about funded conferences.

It took me long time to know that conference attendance carry some points in promotion criteria but no one told us because nobody is mentoring you to give you information about anything. In short, you just struggle with accessing information. Many of our "ogas" (senior colleague) have information on sponsored conferences that is all-expenses paid, but they will hardly tell you. Thank God for Internet though, but surfing the Net takes time... (Mrs. K.; Faculty of Agricultural Science) 
About five of the participants mentioned data management and research methods that they considered to be pivotal areas where many female academics will need mentoring. A young academic in her reproductive age opined,

It's easy for our male colleagues to sit with each other and learn statistical tools for data analysis and other relevant soft wares. Usually, this is done at their spare time when need to socialize. Where do I have such time? It is not that it's not important, but I have a young son who I leave with my nanny every day, so I practically rush home to care for my son. Conclusion, no time to socialize for me, so how do I cope in my researches? Not that I am not ok, but can be better if given the opportunity. (Mrs. J.; administration)

In obvious despair about the state of mentoring activities, one participant argued that formal mentoring cannot occur within the Nigerian university system. Fewer than half of the participants (12 of them) observed that it was possible to achieve success alone by being hardworking, maintaining that what is known as mentoring within our universities is a mere translation of the godfather syndrome, synonymous with the Nigerian political terrain that has found its way into academics. The remaining 29 of those interviewed argued that mentorship in Nigerian universities may have its own variant, but described it as essential to surviving the murky academic water. Additionally, some of the participant sated that senior colleagues' definition of "mentees" were actually slaves who did their biddings and are used for variety of selfish personal activities.

When asked, a number of them had affirmed that they had mentors who have helped them professionally, and they were quick to point out several stories about a mentor-mentee relationship that went awry, a common experience in the ivory towers. Some of the respondents shed more light:

Mentorship is like guiding somebody, but what we have is someone robbing your time. They tell you, "you sit there," "go and buy this," "cover that lectures." Mentoring should be like, "how many papers do you have," "let me give you an idea," "I want to see your paper in 2 weeks." They don't want you to progress, that is wickedness. Only a few want you to rise. Left to them when they climb they put away the ladder I don't think we need mentoring as it were here. What women need is the enabling environment that will make room for easy joggling between family and workplace. Mentoring in our environment, you will have to serve your mentors, but in the developed societies, it is the mentor that serves the mentee. You do extra work than someone that do not have mentors. I see it as an extra luggage. In this society, mentoring will take more from you than doing you good. The only thing I need is the system that balances the family and work place. The system does not see the needs of women who also have responsibilities. E.g., the university needs a crèche for female lecturers who are nursing mothers especially in examination periods like this. I wake up in the morning to perform wifely and motherly roles and have to be in school for examinations as early as 7 a.m. These are the issues not mentoring. Other things that are germane and can affect women not mentoring. (Mrs. B.; MSc candidate, Faculty of Sciences)

Mentoring is good, but in this part of the world, it has been really abused. You know our culture kind of supports eye service and for us here, what we call mentoring is just another opportunity to have caucuses and alliances. 
What time do I have? If it was organized by the university to be somewhat formal, this will be a different pot of kettle. I will rather just work hard and believe God to help me where I cannot help myself. (Mrs. O.; Faculty of Pharmacy)

I am all for having a formalized form of mentoring. But if you think the university is apart from what is happening in the larger society, then I beg to disagree. People mentor those who they know will serve their own interest in the system. So many things are happening. That is why I don't believe that the form mentoring they are doing here. It is like having godfathers in politics to promote your cause. To get older women is even worse, because many of them hardly have your time. Maybe they are entangled with their own women things, but sincerely many of them are too self-centered that they have little or no time for younger academic. The men have better advantage since they are more, they have a greater window of opportunity to socialize and possibly find mentors. (Dr. [Mrs.] A.; administration)

More disturbing about this view point was the way mentoring was perceived by a significant number of female academics who do not find the present forms of informal mentoring relationships safe, worth-while and beneficial. Evidences from researches have shown that mentoring activities benefits mentees tremendously and enhance their career progression.

\section{Lived Experiences of Female Academic With Regards to Academic Mentoring}

Despite the pervasive notion about the importance of mentoring, 15 of the participants categorically expressed their displeasure about the untidiness associated with the process of mentoring especially within a cultural milieu. Many of them observed that culturally, women who are well read are often perceived as inherently arrogant who may not be a good home makers and wives. It is within this prevailing cultural expectation that many young female academics are compelled to play the script of the "good wife" who must carry out household chores regularly, nurture her children, and attend to the extended family needs.

An important observation at this point was that there was divergent opinion about the lived experiences of women within child bearing age and those who had grown children, based on their chronological/biological ages. Hence, seven participants still nursing children stated that it was very challenging submitting themselves to mentors due to the complexity of their roles at home and at work, especially at the initial point of recruitment as an academic staff. Incidentally, a significant number of them are undergoing training as academic staff and postgraduate students. They argued that their circumstance became more precarious for female academics when their spouses are not in academics as they are more likely to show lack of understanding and consideration over their plight. In many instances, participants disclosed that they are unable to compete favorably with their male counterparts as they are unable to acquire relevant skills, attending training workshops outside the university. Attendance of conferences was greatly impaired and travelling to utilize fellowships opportunities are usually put on hold. Three participants felt that women whose spouses were academics were more likely to show a higher level of consideration. Here are some of the excerpts:

Men have time; they can leave their homes in the morning and be in the office till 7 p.m. But women don't have that time. We run up and down for our children to go to school and we get tired after doing a little work. At the end of the day, papers and thesis are left unwritten, coupled with emotional and 
psychological problems. It is worse if a woman is married to a nonacademic who might not understand the job very well. We may not meet up $100 \%$, at least $80 \%$. (Mrs. S.; MSc candidate, Faculty of Social Sciences)

Young female academics are not doing badly, although as a woman, we have a lot of challenges to tackle especially in the home front. (Mrs. F.; Msc Candidate, Faculty of Education)

On a personal level, I observed that women whose spouses are part of the system here often fair better and such women cope better at work. That is my observation. It's not for those like us, somehow you are left alone. (Mrs. R.; PhD student, Faculty of Education)

\section{Gender Issues as Reality in Women's Mentoring Experiences}

In capturing the lived experiences about mentoring experiences in the university, against the backdrop of a patriarchal set up, the participants were asked their relationship with male and the possibility of having them as mentors. Responses varied from participant to participant. Ten women disclosed that they have males as their mentors and they have actually enjoyed working with them. The participants added that arriving at a healthy family work balance usually challenging, which usually left very little time for mentoring activities. They however noted that many of the young female academics are beginning to have males as their academic mentors, even though they are well aware of the complexity that mentor-mentee relationship will pose within the social context of the study location. Some of the participant disclosed that the tendency to be confronted with rumors that such women are having sexual affairs with their male mentors is very high. This view appeared to be dominant among these category of participants taking into account that majority of the participant are married women. Here are some of the excerpts:

A woman has to pay careful attention. If they are men, rumors may be going round that she is going out with so and so professor or lecturer. (Dr. [Mrs.] T.; Faculty of Sciences)

Females don't usually have time for female colleagues. Maybe what is disturbing them is the performing of wife and mother roles at home, before I finish work and home challenges. Maybe that is why we don't have much of female mentors. Secondly, the composition of male to female is too high like 80 to $20 \%$. Thirdly, so far you choose a male mentor there might be rumors of infidelity. (Mrs. S.; PhD candidate, Faculty of Social Sciences)

We don't have much female senior colleagues. In African setting, there is that fear of harassment. The society even insinuates it sometimes. The young female academic keep away from the male and unfortunately we don't have much senior females. (Dr. [Mrs.] O.; Faculty of Social Sciences)

Lack of other female counterparts in the higher cadre to mentor us the younger ones. Women go through some life situations that men find it hard to relate with. Harassments could come forth from mentoring relationship between males and females. Lack of believe in women by the male lectures. The system is not doing enough to support the peculiarities of females like a crèche for nursing mothers. (Mrs. B.; PhD candidate, Faculty of Sciences) 
A total of 20 maintained that they preferred working with female academics to avoid any form of scandal. They observed that though many older female academics are hardly available, they are usually more empathic and safer to work with without fears of being harassed. Seven of those interviewed were completely indifferent in their preference for a particular gender. For them, the emphasis should be on productivity and professionalism instead of the gender of the person. Another important point identified by young academics revealed that when older female academics attain to positions of leadership in the university, they are likely to be more empathic with the challenges that younger female academics may need to surmount to compete favorably with male counterparts. Three of the participants interviewed in the Faculty of Social Sciences mentioned a female dean who had meetings with all female academic staff to identify their gender needs in a male dominated environment. Issues ranging from office space problems that warranted younger female academic sharing offices with their male counterparts were identified as possible hindrances to female academic staff productivity. Also an issue was the inability to attend international conferences that would give opportunities for young female colleagues to interact with peers across the globe, due to family constraints and child nurturance, as well publication challenges. These young female academics were inspired by her motivation and the fact that efforts were made at the faculty levels to pay closer attention to the female academics. They however noted with dismay that there was no structure to sustain the proposed formal mentoring relationship, and so could not continue.

One of the academics who had benefitted from the interaction stated,

"I wished the former dean had continued with the proposed idea, it would have been rescue mission for people like me. It is not easy combining school and work here were there are no supportive infrastructures. (Mrs. S.; PhD candidate, Faculty of Social Science)

\section{Discussion of Findings}

Despite efforts geared toward bridging this unhealthy disparity in terms of access and participation in higher education, gendered disparities still exist. The findings revealed that there are no concrete formal structures in place in the university to be able to cater for the growing needs of newly recruited female academics. Many of these younger academics are "green" and lack adequate information on the university operations and guidelines for promotion. For instance, some of the female academics do not know that in many Nigerian universities, teaching counts, but attracts very little marks compare research publication outputs. The latter has higher value when it comes to promotion. Another vital area of need is information regarding publishing articles. Academic writing is a skill, which is teachable and transferable from senior academics to younger female academics. This critical gap was identified and supported by a Carnegie-sponsored project that was aimed at building capacity of young female academics. A few young female academics benefited from the project as they were sent on overseas funded training. The training provided those who participated opportunities to write up their dissertation. However, the mentoring component was not really emphasized. As a terminal project, the funding has stopped and no similar initiative is currently in place to address the growing gendered disparities in scholarly output and mentoring opportunities for young female academics.

Finding also revealed that majority of young female academics consider mentoring valuable tool through which one can successfully climb the ladder of success when properly engaged. Despite their knowledge about the importance of mentoring in the universities, almost half (12) of the current young female academics in OAU disclosed that they are not truly been mentored by older female colleagues who could have been able to provide academic leadership to younger ones. This supports 
earlier findings from a similar study conducted in University of Benin (Ofoevwe and AgbontaenEghafona; 2011): Some female academics still undergoing postgraduate training are of the opinion that mentorship could be perverted by some older academics. In extreme cases, these younger colleagues are made to run errands instead of equipping them with requisite skills and providing them with relevant information that will increase career advancement.

Findings revealed that mentoring relationships are unstructured in most relationship after the postgraduate studies, but formal under the guise of the supervisor-supervisee relationship. This finding supports Okurame (2006), who said that mentoring in universities are essentially informal. Mentoring is usually confined to the thesis writing, and may not incorporate other areas of needs for the female academics. However, several factors like the personality of the supervisor, level of exposure, perception of the importance of mentoring, and willingness to transfer skills can actually determine if such supervisors will go beyond the statutory requirement for mentoring their supervisees. Indeed, very few (five) participants identified their thesis supervisor as their mentor.

There is glaring evidence that female participation in higher education in sub-Saharan Africa is low, which is revealed in the male to female academic staff ratio. The few women in academics-who often times suffer a setback career-wise and a delay in the path of academic progress, owing largely to lack of mentors-need to be encouraged. The resultant effect is the increase in incompetent and locally bred female academics. An appreciable number of female academics who are the participants in this study are married and have children. The complex responsibilities associated with these multiple roles of such women paints vivid pictures of unfocused persons which is the antithesis of the stereotypical model of who should be a good academic. This view point is supported by Cress and Hart (2009), who affirmed that academics as an enterprise is established on male-centric values and ideologies. The proclivity to discourage women, especially those undergoing training in a maledominated environment where academic success becomes largely remote because of their genderspecific needs that are largely unmet, is very strong. Hence, Mason and Goulden (2002) and Ogbogu (2011) affirmed that male academics have more leverage in achieving success and advancing in their professional path because they are relatively less encumbered with family responsibilities.

Notably, female participation in higher education is generally low, and it behooves university management to pay greater attention by engaging more productively in ideas about formalizing mentoring structures for upcoming female academics. Paying very little or no attention to the plight of women as they struggle to compete with their male counterparts under unequal platforms will result in creating female academic staff members who are grossly incompetent and who may find it challenging to favorably compete with peers from other cultures, especially in an era of globalization where information flow and technical know-how re imperative.

In conclusion, this is basically an exploratory study in a premier university that was ranked the best university in Nigeria in 2014. Findings may therefore not be generalizable across the various universities in Nigeria as it stands, but they do give an emic (insiders') perspective of the experiences of female academics in one of the earliest universities in Nigeria. We suggest that a lot more needs to be done in the area of subjective wellbeing and evaluation of career progression among female academics: a study that can capture the state of women academics in Nigeria. There is also a need to assess, in a future study, turnover rates and retention of young female academics in their reproductive age in Nigerian universities based on university ownership, that is, if it is owned by government or privately owned. 


\section{References}

Allen , T., Eby, L., Poteet, M., Lentz, E., \& Lima, M. (2004) Career benefits associated with mentoring or protégés: A meta-analyses. Journal of Applied Psychology, 89, 127-136.

Bush, T. (2006). The National College of School Leadership: A successful English Innovation. Phi Delta Kappan, 87, 508-511.

Connor, M., \& Pokora, J. (2007) Coaching and mentoring at work: Developing effective practice. Berkshire, United Kingdom: Maidenhead Open University Press.

Famade, O., Omiyale, G., \& Adebola, Y. (2015). Towards improving funding of tertiary institutions in Nigeria. Asian Journal of Social Sciences, 3, 83-90.

Federal Ministry of Women Affairs and Social Development. (2006). National gender policy. Abuja, Nigeria: Author.

Glike, P., \& Fiske, S. (1991). The ambivalent sexism inventory: Differentiating between hostile and benevolent sexism. Journal of Personality and Social Psychology, 70, 491-517.

International Organisation for Migration. (2014). Need assessment of Nigerian educational sector. Retrieved from https://nigeria.iom.int/sites/default/files/newsletter/ANNEX\%20XXIV\%20REPORT\%20OF\%2 0NEEDS\%20ASSESSMENT\%20IN\%20EDUCATION\%20SECTOR\%202014.pdf

Kanter, R. (1977). Men and women of the corporation. New York, NY: Basic Books.

Levinson, W., Kaufman, K., Clark, B., \& Tolle, S. W. (1991). Mentors and role models of women in academic medicine. The Western Journal of Medicine, 154, 423-426.

McIntosh, M. (2009). Yoruba women, work and social change. Ibadan, Nigeria: Bookcraft.

Obafemi Awolowo University. (2016). History of Obafemi Awolowo University. Retrieved from http://www.oauife.edu.ng/administration/student-affairs/students-handbook/history/

Ofoevwe, C., \& Agbontaen-Eghafona, K. (2011). Mentors and mentoring amongst academic staff in Nigerian tertiary institution: A study of University of Benin, Edo State. In A. A. Olowu (Ed.), Mentoring: A key issue in human resource (pp. 216-238). Ife, Nigeria: Ife Centre for PsychologIA.

Ogbogu, C. O. (2009). An analysis of female research productivity in Nigerian universities. Journal of Higher Education Policy and Management, 31, 17-22.

Ogbogu, C. O. (2011) Gender inequality in the academia evidences from Nigeria. Contemporary Issues in Educational Research, 4, 1-8.

Okruramen, D. (2006). Career outcomes of job experience and gender occurrence of mentoring. Ibadan Journal of the Social Sciences, 4, 111-119.

Okruramen, D. (2008) Mentoring in the Nigerian academia: Experiences and challenges. International Journal of Evidence Based Coaching and Mentoring, 6.

Oloruntoba, A., \& Ajayi, T. (2006). Gender and research attainment in Nigerian agricultural universities. JHEA/RESA, Council of Development of Social Science Research in Africa, CODESRIA, 4, 83-98.

Oluwole, D., Hammed, A., \& Awaebe, J. (2010). Patterns of stress, social support, and mental health among Nigerian women. Retrieved June 10, 2014, from 
http://www.advancingwomen.com/awl/awl_wordpress/patterns-of-stress-social-supportandmental-health-among-nigerian-women/

Sambunjak, D., Straus, S., \& Marusic, A. (2006). Mentoring in academic medicine: A systematic review. JAMA, 296, 1103-1115.

Smith, J., Flowers, P., \& Larkin, M. (2009). Interpretative phenomenological analysis: Theory, method and research. London, United Kingdom: SAGE.

Uwaezuoke, O., \& Ezeh, M. (2008). Implications of missionary education for women in Nigeria: A historical analysis. Journal of International Women's Studies, 10, 186-197.

Wasserstein, A., Quistberg, A., \& Shea, J. (2007). Mentoring at the University of Pennsylvania: Results of a faculty survey. Society of General Internal Medicine, 22, 210-214.

Winesfield, A. H., \& Jarret, R. (2001). Occupational stress in university staff. International Journal of Stress Management, 8, 285-298.

Woods, L., Priest, H., \& Roberts, P. (2002). An overview of different approaches to the interpretation of qualitative data: Part 2: Practical illustration. Nurse Researcher, 10, 45-51.

The Journal of Educational Research and Practice provides a forum for studies and dialogue that allows readers to better develop social change in the field of education and learning. Journal content may focus on educational issues of all ages and in all settings. It also presents peer-reviewed commentaries, book reviews, interviews of prominent individuals, and additional content. The objectives: We publish research and related content that examines current relevant educational issues and processes aimed at presenting readers with knowledge and showing how that knowledge can be used to impact social change in educational or learning environments. Additional content provides an opportunity for scholarly and professional dialogue regarding that content's usefulness in expanding the body of scholarly knowledge and increasing readers' effectiveness as educators. The journal also focuses on facilitating the activities of both researcher-practitioners and practitioner-researchers, providing optimal opportunities for interdisciplinary and collaborative thought through blogging and other communications.

Walden University Publishing: http://www.publishing.waldenu.edu 